\title{
A simple correlation for prediction of the liquid slug holdup in gas/non-Newtonian fluids: Horizontal to upward inclined flow
}

\author{
Jing-yu $\mathrm{Xu}^{*}$ \\ LHO, Institute of Mechanics, Chinese Academy of Sciences, Beijing 100190, China
}

\section{A R T I C L E I N F O}

\section{Article history:}

Received 16 January 2012

Accepted 28 June 2012

Available online 10 July 2012

\section{Keywords:}

Gas/non-Newtonian fluid flow

Liquid slug holdup

Inclined pipes

\begin{abstract}
A B S T R A C T
This paper studies the liquid slug holdup of gas/non-Newtonian fluids in horizontal and inclined pipes. The results of the study show that the liquid slug holdup significantly increases for a given mixture velocity as the liquid phase becomes more shear-thinning. A new empirical correlation for estimating the liquid slug holdup is developed as a function of the Reynolds of liquid phase and inclination angle. The proposed equation is based on measured data consists of 271 data points with inclination angles ranging from $0^{\circ}$ to $75^{\circ}$ from horizontal. A good agreement is obtained between theory and experimental data. These results substantiate the general validity of the correlation presented for prediction of the liquid slug holdup in gas/non-Newtonian two-phase slug flow.
\end{abstract}

(c) 2012 Elsevier Inc. All rights reserved.

\section{Introduction}

Two-phase slug flow occurs in a wide range of practical applications in the chemical, oil and process industries. For example, in the petroleum industry a gas-liquid flow often occurs in hilly terrain pipelines and downcomer pipes extending from offshore production platforms to sea floors. In recent years, considerable effort has been made to study the flow characteristics of gas-liquid slug flow. The liquid holdup in the liquid slug is an important variable, which is required as a closure relationship for slug model. In particular, the evaluation of the liquid slug holdup is important for inclined pipes since it is the main contributor to the hydrostatic pressure gradient.

For the case horizontal flows, Gregory et al. [1] investigated an air-oil slug flow in pipes with two different diameters. A correlation was presented for the liquid slug holdup and showed that the holdup was correlated quite well with respect to the slug mixture velocity. Andreussi and Bendiksen [2] incorporated pipe diameter, inclination angle and physical properties into a semiempirical correlation for the gas holdup in the liquid slug. The results showed that the effects of surface tension and gas density on the gas holdup were important. Maley and Jepson [3] investigated the liquid holdup and length of the mixing zone in the liquid slug. Their data and observations provided insight into the characteristics of the mixing region. For the case inclined flows, Abdul-Majeed [4] presented the empirical equation for estimating the liquid slug holdup in horizontal and slightly as a function of fluids viscosities

\footnotetext{
* Tel.: +8610 8254 4179; fax: +861062561284.

E-mail address: xujingyu@imech.ac.cn
}

and inclination angle. Felizola and Shoham [5] and Gomez et al. [6] developed a unified correlation for the entire range of inclination angles, respectively. However, these methods are entirely empirical in nature, and therefore the extrapolation beyond the range of experimental conditions must be treated with reserve.

The mechanistic method for prediction of liquid slug holdup was first introduced by Barnea and Brauner [7]. They introduced the hypothesis that the liquid slug holdups were the same as those on the slug-dispersed bubble transition boundary under the same input superficial velocities. A physical model for the prediction of gas holdup in the liquid slug was presented and but its accuracy was sensitive to the correct bubble-slug transition boundary. Zhang et al. [8] attempted to develop a unified mechanistic model for the liquid slug holdup based on a balance between the turbulent kinetic energy of the liquid phase and the surface free energy of dispersed spherical gas bubbles. However, it is complicated and verified based on their own data only.

The researches mentioned above focus on the slug flow in gas/ Newtonian fluid system. Experimental data acquired for the slug flow in gas/non-Newtonian fluid system $[9,10]$ have shown that the effect of the fluid physical properties on the slug holdup cannot be ignored. A survey of the past literature shows that few experiments has been reported till date to investigate on the liquid slug holdup for the case of a two-phase flow in inclined pipes, especially for the system with non-Newtonian fluid. In order to extend the knowledge of the liquid slug holdup, we firstly have made an experimental investigation of the influence of liquid phase properties on the liquid slug holdup for horizontal and inclined flows, and hereafter presented a correlation based on up-to-date data that is simple and takes correctly the non-Newtonian fluid effects. 


\section{Nomenclature}

$V_{M} \quad$ mixture velocity, $\mathrm{m} / \mathrm{s}$

$V_{S L} \quad$ superficial liquid velocity, $\mathrm{m} / \mathrm{s}$

$V_{S G} \quad$ superficial gas velocity, $\mathrm{m} / \mathrm{s}$

$k \quad$ fluid consistency coefficient, Pa $\mathrm{s}^{\mathrm{n}}$

$n \quad$ flow behaviour index

$D \quad$ pipe diameter, $m$

$\operatorname{Re}_{L} \quad$ Reynolds number of liquid phase

$\begin{array}{ll}\text { Greek } & \\ \alpha & \text { liquid holdup } \\ \alpha_{s} & \text { liquid slug holdup } \\ \mu_{\text {eff }} & \text { effective viscosity, Pa s } \\ \theta & \text { pipe inclination angle } \\ \rho_{L} & \text { liquid phase density, } \mathrm{kg} / \mathrm{m}^{3}\end{array}$

$\mu_{\text {eff }}=D^{1-n} 8^{n-1} k \cdot V^{n-1}$

\section{Experimental set-up and fluid characteristics}

The experiments were performed using Perspex tubing of $60 \mathrm{~mm}$ in diameter. The experimental layout included two $10 \mathrm{~m}$ long pipe branches connected by a U-bend that could be inclined to any angle, from a completely horizontal to a fully vertical position. The liquid slug holdup was measured by the gamma-ray attenuation technique, which installed at $5 \mathrm{~m}$ from the entry point. A typical signal recorded in the liquid holdup was shown in Fig. 1. Air originated from a compressor pump and was routed through a gas tank and a regulating valve to maintain a constant pressure, after which it passed through a gas mass flow-meter. The liquid phase was conveyed from the liquid phase tank and circulated through the system by a centrifugal pump. The volumetric flow rates of all phases were regulated independently and measured by a thermal mass flow-meter for the gas phase and an electromagnetic flow-meter for the liquid phase, respectively. Flow patterns were recorded using a high-speed video camera, and the flow patterns for each test condition were recorded and observed later in slow motion. Pressure gradient in the test section was measured by two absolute pressure transducers, which used to assist flow pattern identification. The details of the flow-loop could be found in the previous works [9].

Tap water was used as the Newtonian fluid and carboxymethyl cellulose (CMC) solutions with three different concentrations as the non/Newtonian fluids. As expected, CMC solutions were shear-thinning fluids whose appropriate Reynolds number can be obtained as:

$\operatorname{Re}=\frac{\rho_{L} D V}{\mu_{\text {eff }}}$

where $V, D$ and $\rho_{L}$ are the fluid velocity, the pipe diameter and the density of liquid phase, respectively. The effective viscosity, $\mu_{\text {eff }}$ is defined as:

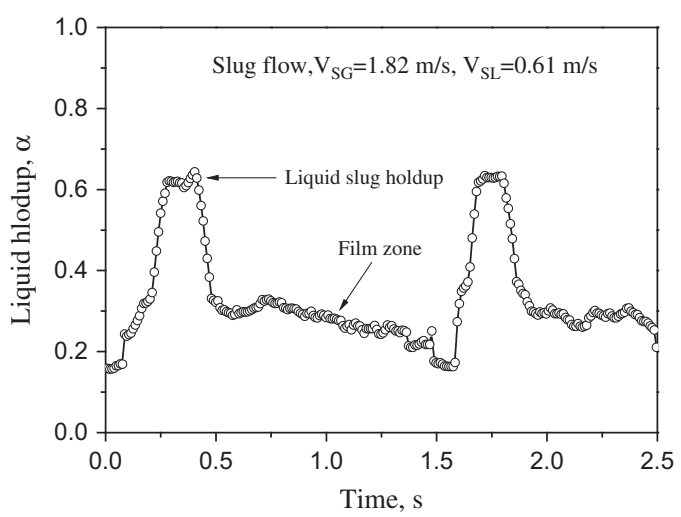

Fig. 1. Typical signal of the liquid slug holdup by the gamma-ray attenuation technique. where $k$ and $n$ are referred to as the fluid consistency coefficient and the flow behaviour index, respectively.

The values of $k, n$ and other properties of the CMC solutions were given in Table 1. For the fluids used in this work, the rheological behaviour of CMC solutions was measured before and after each run at constant liquid flow rate. The average deviation of the effective viscosity is less than $4.8 \%$. A total of 360 experimental data were measured for the liquid slug holdup of five different inclination angles in horizontal and downward pipes.

\section{Analysis and results}

The experiment results are presented on the liquid slug holdup, which includes gas/Newtonian fluid and non-Newtonian fluid systems. The developed correlations for gas-liquid slug flow are verified with experimental results in this work and others in the literature.

\subsection{Gas/Newtonian fluid system}

Fig. 2 presents the evaluation of the predicted liquid slug holdup with experimental data of the present work by using four different methods for gas/Newtonian fluid horizontal flow. The predictions show a similar performance for three methods $([1,5,6])$, but overestimation of the holdup by using the correlation of Abdul-Majeed [4]. This is not surprising for the correlation that is derived chiefly from the data of high viscosity liquid phase. As be seen in the Fig. 2 that, with the mixture velocity increasing, the liquid slug holdup gradually decreases. Fig. 3 gives the liquid slug holdup against the mixture velocity in inclined pipe $\left(\theta=15^{\circ}\right)$. The model of Gomez et al. [6] is expected to perform best because of modeling including the effect of Reynolds. Furthermore, a comparison between Figs. 2 and 3 shows that, with the inclination angle increasing, the liquid slug holdup declines. Similar tendency is also obtained in the experimental works of Felizola and Shoham [5].

Because there are no enough experimental data of the liquid slug holdup in inclined pipes for a gas/Newtonian fluid system, in the present study we only amend the coefficients of the model of Gregory et al. for a gas/Newtonian fluid horizontal flow as:

Table 1

The physical properties of the fluid measured at $20^{\circ} \mathrm{C}$ and $0.101 \mathrm{MPa}$.

\begin{tabular}{lllll}
\hline Liquid phase & $\begin{array}{l}\text { Concentration } \\
(\mathrm{kg} / \mathrm{m})\end{array}$ & $\begin{array}{l}\text { Density, } \\
\rho(\mathrm{kg} / \\
\left.\mathrm{m}^{3}\right)\end{array}$ & $\begin{array}{l}\text { Fluid } \\
\text { consistency } \\
\text { coefficient, } k \\
\left(\text { Pa s }^{\mathrm{n}}\right)\end{array}$ & $\begin{array}{l}\text { Flow } \\
\text { behavior } \\
\text { index, } n\end{array}$ \\
\hline CMC-1 solution & 1.0 & 999.9 & 0.089 & 0.798 \\
CMC-2 solution & 2.0 & 1000.0 & 0.469 & 0.658 \\
CMC-3 solution & 3.0 & 1000.4 & 0.972 & 0.615 \\
\hline
\end{tabular}




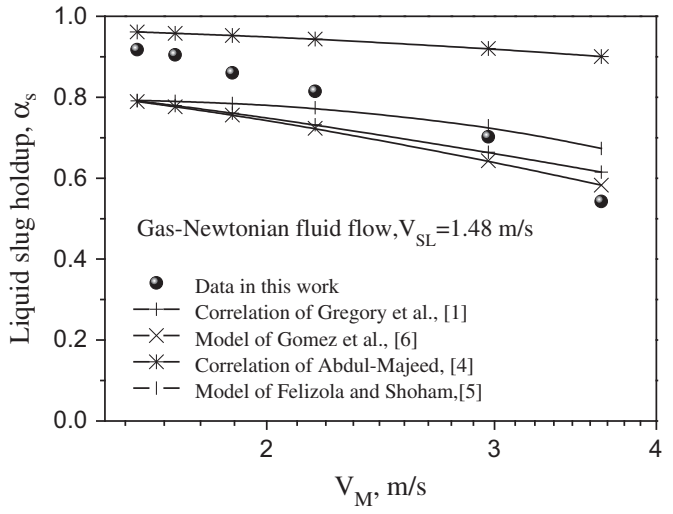

Fig. 2. Evaluation of the predicted liquid slug holdups with experimental data by using four different methods for gas/Newtonian fluid horizontal flow.

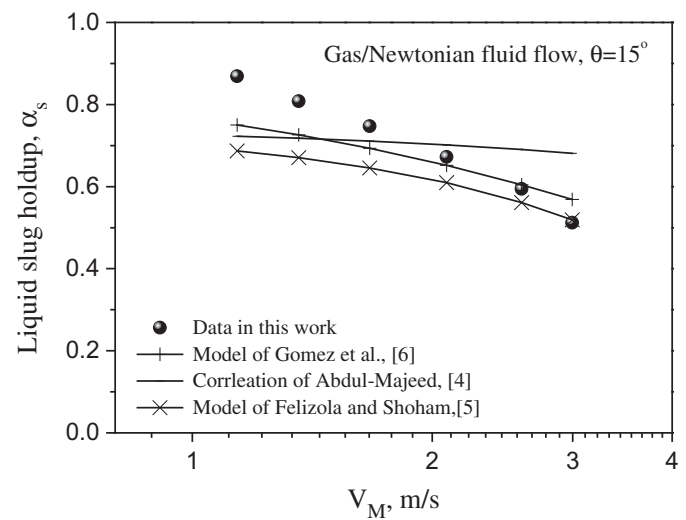

Fig. 3. Evaluation of the predicted liquid slug holdups with experimental data by using three different methods for a gas/Newtonian fluid upward inclined flow.

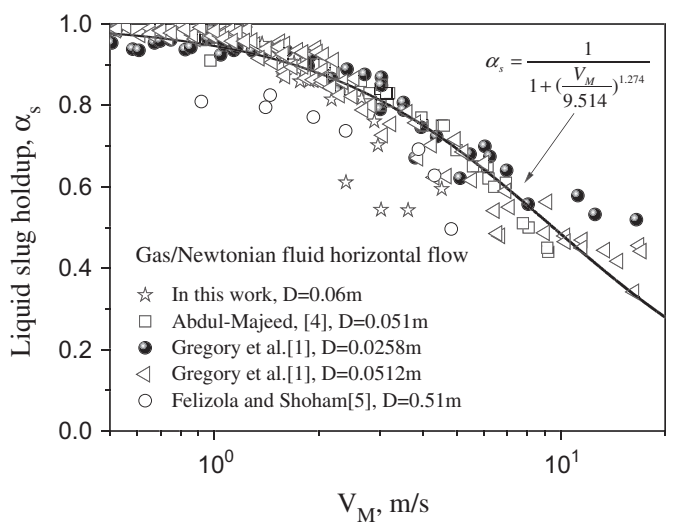

Fig. 4. Comparison of the predicted liquid slug holdups with experimental data of the present work and others in the literature for gas/Newtonian fluids horizontal flow.

$\alpha_{s}=\frac{1}{1+\left(\frac{V_{M}}{9.514}\right)^{1.274}}, \quad 0.1 \mathrm{~m} / \mathrm{s} \leqslant V_{M} \leqslant 20 \mathrm{~m} / \mathrm{s}$

As can be seen in Fig. 4, the 228 data points collected include pipe diameters from $0.0258 \mathrm{~m}$ to $0.06 \mathrm{~m}$ and different Newtonian fluids, including high-viscosity oil phase. The data have been acquired for a horizontal flow. Better fitting results are obtained with an average error of $0.8 \%$ and an average absolute error of $5.14 \%$,
Table 2

Statistical parameters for experimental and predicted liquid slug holdup for horizontal and upward slug flows.

\begin{tabular}{llcl}
\hline Gas-liquid systems & $\begin{array}{l}\text { Data } \\
\text { points }\end{array}$ & $\begin{array}{l}\text { Average error, } \\
E 1(\%)\end{array}$ & $\begin{array}{l}\text { Average absolution } \\
\text { error, E2 (\%) }\end{array}$ \\
\hline $\begin{array}{c}\text { Gas/CMC-1 } \\
\text { solution flow }\end{array}$ & 95 & 2.05 & 7.66 \\
$\begin{array}{c}\text { Gas/CMC-2 } \\
\text { solution flow }\end{array}$ & 89 & -7.59 & 11.61 \\
$\begin{array}{c}\text { Gas/CMC-3 } \\
\text { solution flow }\end{array}$ & 87 & -2.48 & 11.56 \\
\hline
\end{tabular}

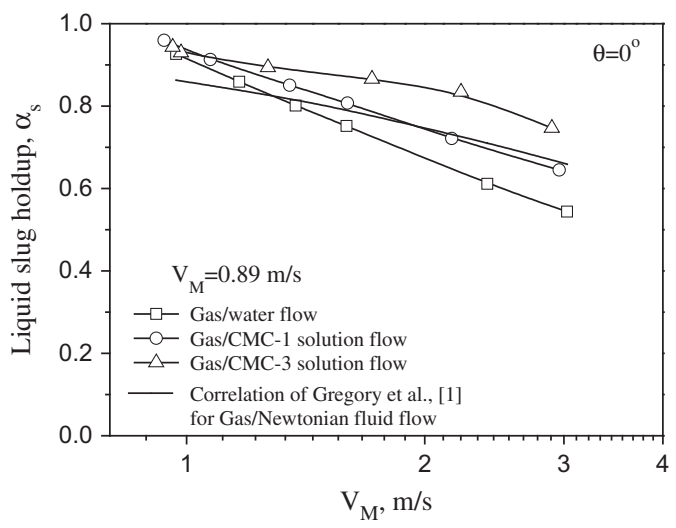

Fig. 5. The effect of fluid physical properties on the liquid slug holdup in horizontal pipes.

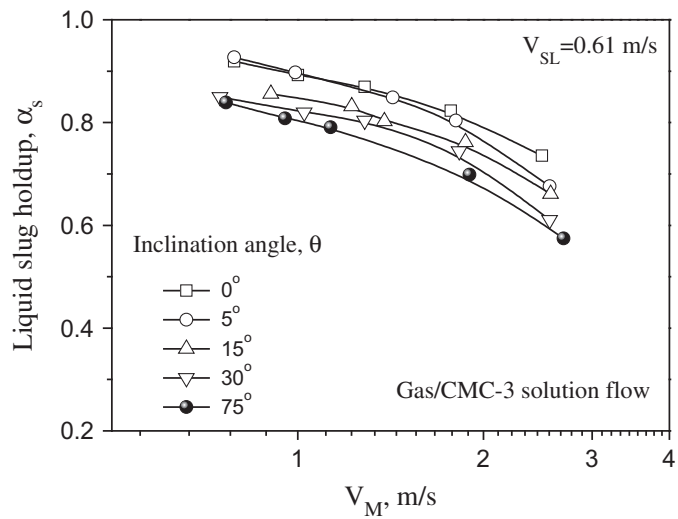

Fig. 6. The effect of pipe inclination on the liquid slug holdup for gas/nonNewtonian fluids inclined flow.

respectively. Moreover, the data with high mixture velocity are scattered and the agreement is worse. The failure to predict the results in this case may be due to the fact that the effects of pipe diameter are not considered by this model.

\subsection{Gas/non-Newtonian fluid system}

Data from three different concentration solutions have been used to investigate the liquid slug holdup and develop the present study correlation. A summary of the experimental database for the liquid slug holdup can be found in Table 2 .

Fig. 5 presents the effect of fluid physical properties on the liquid slug holdup for gas-liquid horizontal slug flow. It can be seen 


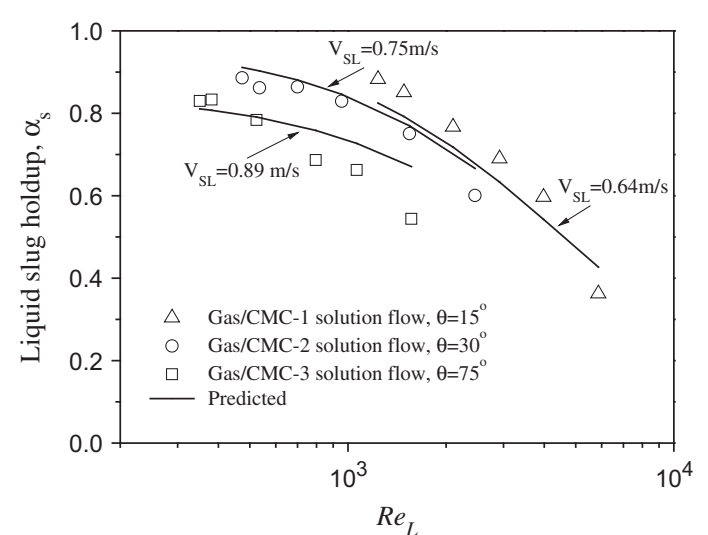

Fig. 7. A typical comparison between experimental data and the predicted of Eq. (4) for gas/non-Newtonian fluids inclined flows.

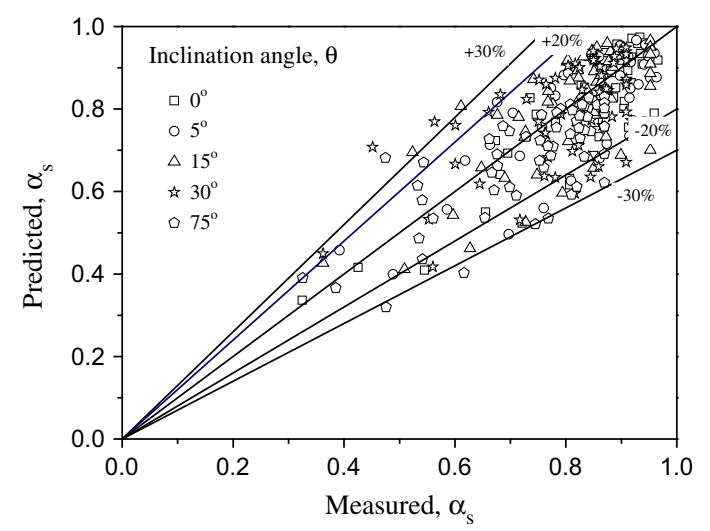

Fig. 8. Comparison between the experimental data with the predicted of Eq. (4) for gas/non-Newtonian fluids horizontal and inclined flows.

that the liquid slug holdup $\left(\alpha_{s}\right)$ significantly increases for a given mixture velocity as the liquid phase becomes more shear-thinning (i.e., lower value of $n$ ). Especially with the mixture velocity increasing, the difference becomes larger. Fig. 6 shows the experimental results for the liquid slug holdup against the mixture velocity with different inclination angles. The data are grouped into five groups, namely, $0^{\circ}, 5^{\circ}, 15^{\circ}, 30^{\circ}$, and $75^{\circ}$ from the horizontal. The figure shows clearly the variation of the liquid slug holdup with inclination angle. As the inclination angle increases from the horizontal, the liquid slug holdup declines significantly for the same mixture velocity.

An analysis of the measured data indicates that the liquid slug holdup is affected mainly by inclined angle and Reynolds number. Careful examination of the observations indicates that a simple relationship be defined by incorporating the inclined angle and Reynolds number for the slug flow in upward inclined pipe. The trend of the data may be represented by:

$\alpha_{s}=\frac{(1-\sin \theta)^{0.05}}{1+3.166 \times 10^{-5} \mathrm{Re}_{L}^{1.225}}, \quad 0^{\circ} \leqslant \theta \leqslant 75^{\circ}$

where $\operatorname{Re}_{L}=\rho_{L} D V_{M} / \mu_{e f f}$
A typical comparison between experimental data and the predicted of the proposed correlation is shown in Fig. 7. As can be seen, Eq. (4) captures the main trends of the data, namely that the liquid slug holdup decreases with increasing the mixture Reynolds and increases with declining the inclination angle.

Finally, the proposed method for predicting the liquid slug holdup has been checked by plotting all experimental values vs. the predicted ones calculated from Eq. (4). Statistical parameters for the experimental and predicted holdups in horizontal and inclined pipes are presented in Table 2. It can be found that the fitting results are within an average absolute error of $11.61 \%$. Good agreement is obtained between theory and data, as shown in Fig. 8. Most of the predicted values are well inside the $20 \%$ deviation region. These results substantiate the general validity of the model presented for gas/non-Newtonian fluids slug flow.

\section{Summary and conclusions}

Three hundred and sixty experimental runs under slug flow conditions are conducted, including gas/Newtonian fluid and non-Newtonian fluid systems respectively. Data are acquired for the entire range of inclination angles, from horizontal to inclination with $75^{\circ}$. The variations of the liquid slug holdup with inclination angle are observed and measured.

The results from this study show that the liquid slug holdup increases for a given mixture velocity as the liquid phase becomes more shear-thinning. A new simplified correlation is developed in order to fit all the available data of gas/non-Newtonian fluid slug flow. The proposed correlation is based on the Reynolds of the liquid phase and the inclination angle. Comparison between the predicted and measured holdups reveals a reasonable agreement.

\section{Acknowledgment}

The author gratefully acknowledge that the work described here was financially supported by the National Natural Science Foundation of China (No. 10902114).

\section{References}

[1] G.A. Gregory, M.K. Nicholson, K. Aziz, Correlation of the liquid volume fraction in the slug for horizontal gas-liquid slug flow, Int. J. Multiphase Flow 4 (1978) 33-39.

[2] P. Andreussi, K. Bendiksen, An investigation of void fraction in liquid slugs for horizontal and inclined gas liquid pipe flow, Int. J. Multiphase Flow 6 (1989) 937-946.

[3] L.C. Maley, W.P. Jepson, Liquid holdup in large-diameter horizontal multiphase pipelines, J. Energy. Resour. Tech.-ASME 120 (1998) 185-192.

[4] G.H. Abdul-Majeed, Liquid slug holdup in horizontal and slightly inclined twophase slug flow, J. Petrol. Sci. Eng. 27 (2000) 27-32.

[5] H. Felizola, O. Shoham, A unified model for slug flow in upward inclined pipes, J. Energy. Resour. Tech.-ASME 117 (1995) 1-6.

[6] L.E. Gomez, O. Shoham, Y. Taitel, Prediction of slug liquid holdup: horizontal to upward vertical flow, Int. J. Multiphase Flow 26 (2000) 43-49.

[7] D. Barnea, N. Brauner, Holdup of the liquid slug in two-phase intermittent flow, Int. J. Multiphase Flow 11 (1985) 43-49.

[8] H.Q. Zhang, Q. Wang, C. Sarica, J.P. Brill, Unified model for gas-liquid pipe flow via slug dynamics. Part 1: model development, J. Energy. Resour. Tech.ASME 125 (2003) 266-273.

[9] J.y. Xu, Y.x. Wu, Z.h. Shi, L.y. Lao, D.h. Li, Studies on two-phase co-current air/ non-Newtonian shear-thinning fluid flows in inclined smooth pipes, Int. J. Multiphase Flow 33 (2007) 948-969.

[10] J.y. Xu, Y.x. Wu, A simple model for predicting the average void fraction of gas/ non-Newtonian fluid intermittent flows in upward inclined pipes, Chem. Eng. Commun. 196 (2009) 746-753. 